\title{
Association between NFKB1 -94ins/del ATTG Promoter Polymorphism and Cancer Susceptibility: An Updated Meta-Analysis
}

\author{
Xiao Yang, Pengchao Li, Jun Tao, Chao Qin, Qiang Cao, Jinbao Gu, Xiaheng Deng, \\ Jun Wang, Xuzhong Liu, Zijie Wang, Bian Wu, Min Gu, Qiang Lu, and Changjun Yin
}

Department of Urology, The First Affiliated Hospital of Nanjing Medical University, Nanjing 210029, China

Correspondence should be addressed to Min Gu; Lancetgu@aliyun.com and Qiang Lu; doctorlvqiang@sina.com

Received 21 February 2014; Accepted 13 April 2014; Published 7 May 2014

Academic Editor: Ji-Fu Wei

Copyright (C) 2014 Xiao Yang et al. This is an open access article distributed under the Creative Commons Attribution License, which permits unrestricted use, distribution, and reproduction in any medium, provided the original work is properly cited.

\begin{abstract}
Nuclear factor- $\kappa \mathrm{B}$ is associated with the pathogenesis of numerous malignancies, and the functional polymorphism $-94 \mathrm{ins} / \mathrm{del}$ ATTG (rs28362491) in the human NFKB1 gene is associated with cancer risk. Previous studies on the association between the -94ins/del ATTG polymorphism and cancer risk reported conflicting results. To clarify this relationship, we performed a metaanalysis of 21 case-control studies involving 6127 cases and 9238 controls. We used pooled odds ratios (ORs) with their $95 \%$ confidence intervals (95\% CIs) to assess the association. We found that the NFKB1 promoter -94ins/del ATTG polymorphism was significantly associated with cancer risk in four genetic models (ins/ins versus del/del, OR $=1.47,95 \% \mathrm{CI}=1.11-1.93$; dominant model, $\mathrm{OR}=1.26,95 \% \mathrm{CI}=1.03-1.53$; recessive model, $\mathrm{OR}=1.26,95 \% \mathrm{CI}=1.05-1.51$; ins allele versus del allele, $\mathrm{OR}=1.19,95 \% \mathrm{CI}=$ 1.05-1.35). Stratified analyses revealed a significant association between the polymorphism and ovarian, oral, and prostate cancers. Similar results were determined in an Asian population and not in a Caucasian population. Thus, our results suggested that the polymorphism can contribute to cancer risk. Moreover, the polymorphism can exert race- and cancer-specific effects on cancer risk. Further large-scale and functional studies are necessary to elucidate this possible effect.
\end{abstract}

\section{Introduction}

Cancer is a major public health problem worldwide; it is the primary and secondary causes of death in economically developed and developing countries, respectively [1]. The global concern on cancer continues to intensify as a result of the aging and expanding world population and the increasing adoption of cancer-causing habits. The mechanism of carcinogenesis remains largely unknown although genetic susceptibility is a known possible explanation for the interindividual variation in cancer risk [2].

Nuclear factor- $\kappa \mathrm{B}(\mathrm{NF}-\kappa \mathrm{B})$ was initially identified in 1986 as a transcription factor which binds to a $10 \mathrm{bp}$ DNA element in kappa immunoglobulin light-chain enhancer in B cells [3]. The NF- $\kappa$ B family consists of p50 (NF- $\kappa$ B1), p52 (NF- $\kappa$ B2), p65 (RelA), c-Rel (Rel), and RelB. The major form of NF- $\kappa$ B is a heterodimer of the p50 and p65/RelA subunits which are encoded by the NFKB1 and NFKB2 genes, respectively [4]. The human NFKB1 gene is mapped to chromosome 4q24 and encodes a $50 \mathrm{kDa}$ DNA-binding protein (p50) that can act as a master regulator of inflammation and cancer development [5-7].

A common insertion/deletion polymorphism (-94ins/del ATTG, rs28362491) in the promoter region of the NFKB1 gene elicits a regulatory effect on the NFKB1 gene [8]. A previous meta-analysis concluded that the deletion allele serves as a risk or protective allele for cancer susceptibility in Caucasian or Asian populations, respectively; however, it revealed no association between the polymorphism and cancer risk [9]. An increasing number of studies have assessed the association between the NFKB1 promoter -94ins/del ATTG polymorphism and cancer risk [10-12]. However, these studies obtained conflicting results. Therefore, we collected all available data to perform an updated meta-analysis 


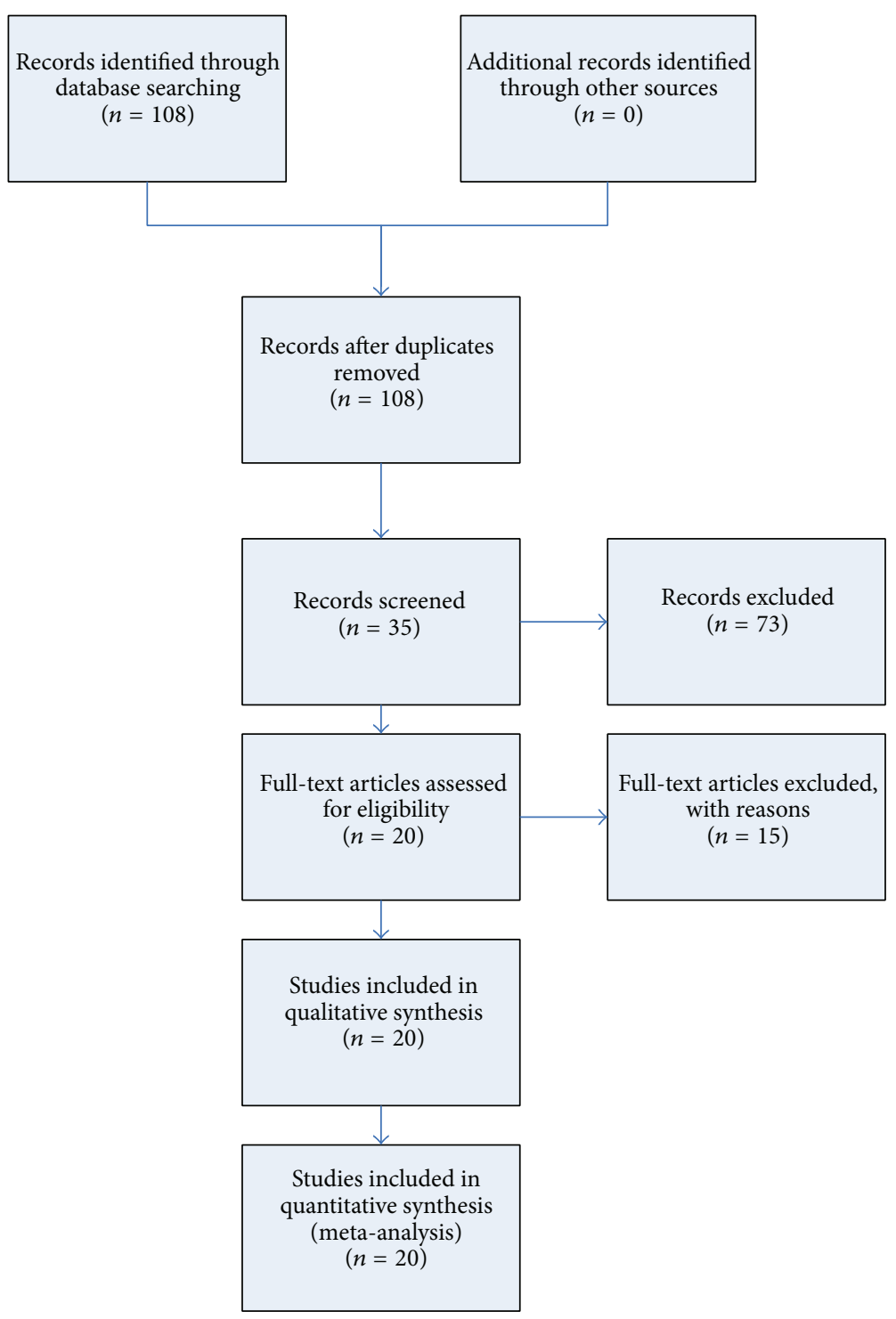

FIGURE 1: Study selection process.

that generates a precise estimation to comprehensively and objectively investigate the association between the NFKB1 promoter-94ins/del ATTG polymorphism and cancer risk.

\section{Materials and Methods}

2.1. Search Strategy and Identification of Relevant Studies. A comprehensive literature search for relevant articles published (last search updated in September 15, 2013) in PubMed (http://www.ncbi.nlm.nih.gov/pubmed/) was performed with the following key words: ("genetic polymorphism," "polymorphism," "SNP," "single nucleotide polymorphism," "gene mutation," or "genetic variant"), ("neoplasm," "cancer," "tumor," “carcinoma," or "carcinogenesis"), and ("NFKB1," "NF- $\kappa$ B1," "nuclear factor kappa B1," "NF kappa $\mathrm{B} 1$," or "nuclear factor $\kappa \mathrm{B} 1$ "). The search was limited to human studies in English. All eligible studies were retrieved. The reviews and references of eligible studies were handsearched for additional relevant publications. The most recent or complete study was selected when more than one publications contain overlapping data. A flow diagram of the study selection process is presented in Figure 1.

2.2. Inclusion Criteria. Case-control studies that evaluated the association of the NFKB1 promoter -94ins/del ATTG polymorphism with cancer risk and described in detail the genotype distributions of the polymorphism in cases and controls were included in this meta-analysis.

2.3. Exclusion Criteria. Studies that were not for cancer research, were only case population, and were duplication of previous publication were excluded in this meta-analysis. 
TABLE 1: Main characteristics of these studies included in this meta-analysis.

\begin{tabular}{|c|c|c|c|c|c|c|c|c|c|c|c|c|}
\hline First Author & Year & Ethnicity & Genotyping method & SC & $\begin{array}{r}\text { Genc } \\
\text { ins/ins }\end{array}$ & $\begin{array}{r}\text { otyping } \\
\text { ins/del } \\
\end{array}$ & $\begin{array}{l}\text { cases } \\
\text { del/del }\end{array}$ & ins/ins & $\begin{array}{c}\text { Control } \\
\text { ins/del }\end{array}$ & del/del & Cancer type & HWE \\
\hline Lin [16] & 2006 & Asian & PCR-RFLP & $\mathrm{HB}$ & 59 & 103 & 50 & 43 & 100 & 58 & OSCC & 0.993 \\
\hline Riemann [17] & 2007 & Caucasian & Pyrosequencing & $\mathrm{HB}$ & 88 & 124 & 30 & 118 & 141 & 48 & Bladder cancer & 0.586 \\
\hline $\mathrm{Bu}[18]$ & 2007 & Caucasian & PCR-RFLP & $\mathrm{HB}$ & 67 & 84 & 34 & 116 & 255 & 67 & Melanoma & $<0.001$ \\
\hline \multirow{2}{*}{ Lewander [11] } & \multirow{2}{*}{2007} & Caucasian & PCR-RFLP & $\mathrm{HB}$ & 63 & 323 & 81 & 116 & 256 & 67 & Colorectal cancer & $<0.001$ \\
\hline & & Asian & PCR-RFLP & $\mathrm{HB}$ & 50 & 101 & 42 & 113 & 266 & 79 & Colorectal cancer & $<0.001$ \\
\hline o [19] & 2008 & Asian & PCR-RFLP & $\mathrm{HB}$ & 62 & 89 & 31 & 20 & 62 & 34 & Gastric cancer & 0.361 \\
\hline Zhang [20] & 2009 & Asian & PCR-RFLP & $\mathrm{HB}$ & 46 & 57 & 14 & 44 & 68 & 31 & Prostate cancer & 0.624 \\
\hline Burnik [21] & 2009 & Caucasian & PCR-RFLP & $\mathrm{HB}$ & 18 & 30 & 2 & 30 & 58 & 12 & GNT & 0.047 \\
\hline Zhou [22] & 2009 & Asian & PCR-RFLP & $\mathrm{HB}$ & 74 & 67 & 22 & 71 & 90 & 42 & NC & 0.177 \\
\hline Tang [23] & 2009 & Asian & PCR-RFLP & $\mathrm{HB}$ & 89 & 92 & 26 & 74 & 108 & 46 & Bladder cancer & 0.565 \\
\hline Andersen [24] & 2010 & Caucasian & Taqman & $\mathrm{PB}$ & 121 & 195 & 62 & 307 & 347 & 102 & Colorectal cancer & 0.801 \\
\hline Zhou [25] & 2010 & Asian & PCR-RFLP & $\mathrm{HB}$ & 108 & 105 & 20 & 135 & 166 & 64 & CSCC & 0.297 \\
\hline Fan $[26]$ & 2011 & Asian & PCR-RFLP & $\mathrm{HB}$ & 78 & 84 & 17 & 76 & 103 & 44 & Ovarian cancer & 0.396 \\
\hline Lin [27] & 2012 & Asian & Taqman & $\mathrm{HB}$ & 116 & 246 & 100 & 81 & 271 & 168 & OSCC & 0.099 \\
\hline Vangsted [28] & 2012 & Caucasian & Taqman & $\mathrm{PB}$ & 110 & 163 & 55 & 665 & 778 & 253 & Multiple myeloma & 0.303 \\
\hline Cai $[10]$ & 2012 & Asian & Taqman & $\mathrm{HB}$ & 401 & 473 & 153 & 379 & 562 & 153 & Renal cell Carcinoma & 0.015 \\
\hline Huo [29] & 2013 & Asian & MassARRAY & $\mathrm{HB}$ & 83 & 82 & 22 & 71 & 103 & 47 & Ovarian cancer & 0.399 \\
\hline Cheng [30] & 2013 & Asian & Taqman & $\mathrm{HB}$ & 42 & 64 & 29 & 81 & 271 & 168 & $\mathrm{HC}$ & 0.099 \\
\hline Mohd Suzairi [31] & ] 2013 & Asian & PCR-RFLP & $\mathrm{HB}$ & 35 & 127 & 75 & 16 & 138 & 83 & Colorectal cancer & $<0.001$ \\
\hline Kopp [32] & 2013 & Caucasian & Taqman & $\mathrm{PB}$ & 128 & 152 & 54 & 109 & 161 & 64 & Prostate cancer & 0.741 \\
\hline $\operatorname{Li}[12]$ & 2013 & Asian & Taqman & $\mathrm{HB}$ & 189 & 269 & 151 & 223 & 324 & 93 & Bladder cancer & 0.156 \\
\hline
\end{tabular}

GNT: Gastroenteropancreatic neuroendocrine tumors; OSCC: oral squamous cell carcinoma; CSCC: cervical squamous cell carcinoma; NC: nasopharyngeal carcinoma; HC: hepatocellular carcinoma; HB: hospital-based study; PB: population-based study; SC: source of controls; HWE: Hardy Weinberg equilibrium.

2.4. Data Extraction. Information was carefully extracted from eligible studies independently by two investigators (Xiao Yang and Pengchao Li) according to the inclusion criteria listed above, and the result was reviewed by a third investigator (Jun Tao). The following data were collected from each study: surname of first author, year of publication, ethnicity, genotyping method, source of controls, frequencies of the genotypes in cases and controls, cancer type, and Hardy-Weinberg equilibrium (HWE) of genotype distribution among controls. Ethnicity was categorised as "Asian" or "Caucasian." Studies that investigated more than one type of cancer were regarded as individual datasets only in subgroup analyses according to cancer type. No minimum number of patients was required for this meta-analysis. Articles that reported different ethnic groups and countries or locations were considered different study samples for each category cited above.

2.5. Statistical Analysis. The strength of association between the NFKB1 promoter -94ins/del ATTG polymorphism and cancer risk was estimated through pooled odds ratio (OR) with its corresponding 95\% CI. Pooled ORs were calculated for insertion allele versus deletion allele, ins/ins versus $\mathrm{del} / \mathrm{del}$, ins/del versus del/del, ins/ins + ins/del versus del/del, and ins/ins versus ins/del + del/del. Subgroup stratification analyses by ethnicity and cancer type were conducted to identify the association of the -94ins/del ATTG polymorphism with cancer susceptibility.
The between-study heterogeneity of the studies included in this meta-analysis was evaluated using the $Q$ and $I^{2}$ statistic tests, where $I^{2}>50 \%$ indicated heterogeneity [13]. The random-effects model was selected when $I^{2}$ was significant ( $>50 \%)$; otherwise, the fixed-effects model was selected. The allele frequencies of the NFKB1 promoter -94ins/del ATTG polymorphism from the respective study were determined by allele counting. In addition, a chi-square test was used to determine whether or not the observed frequencies of genotypes conform to HWE. Pooled OR in the current meta-analysis was performed by weighting individual ORs by the inverse of their variance. The significance of the pooled $\mathrm{OR}$ was determined by the $Z$-test. In addition to the comparison among all subjects, we performed stratification analyses by cancer type (if one cancer type contained only one studies, it was combined into the "other cancers" group) and ethnicity. Begg's funnel plot and Egger's test were adopted to evaluate the publication bias in our meta-analysis $[14,15]$. All statistical analyses were performed by STATA 10.0 software (StataCorp, College Station, TX, USA).

\section{Results}

3.1. Eligible Studies and Meta-Analysis Databases. A total of 21 case-control studies involving 6127 cases and 9239 controls were analysed. The characteristics of all studies are presented in Table 1. The allele and genotype frequencies of the NFKB1 promoter -94ins/del ATTG polymorphism were extracted 
from all eligible studies. In total, this meta-analysis included 3 bladder cancer studies, 4 colorectal cancer studies, 2 ovarian cancer studies, 2 oral cancer studies, 2 prostate cancer studies, and 8 studies with the "other cancers." Of the 21 studies, 14 were conducted among Asians and 7 were conducted among Caucasians. All cases were clinically pathologically confirmed.

The results of HWE test for the genotype distribution in the control population are shown in Table 1. Six of the eligible studies were not in HWE $[10,11,18,21,31]$.

3.2. Quantitative Synthesis. The pooled ORs of the included case-control studies revealed a statistically significant association between the NFKB1 promoter -94ins/del ATTG polymorphism and cancer risk across the four genetic models ins/ins versus del/del, $\mathrm{OR}=1.47,95 \%, \mathrm{CI}=1.11-1.93$; dominant model, $\mathrm{OR}=1.26,95 \% \mathrm{CI}=1.03-1.53$; recessive model, $\mathrm{OR}=1.26,95 \% \mathrm{CI}=1.05-1.51$; and ins allele versus del allele, $\mathrm{OR}=1.19,95 \%, \mathrm{CI}=1.05-1.35$ (Table 2, Figure 2). Stratified analyses also revealed a significant association between the polymorphism and ovarian, oral, and prostate cancers in the various models. Ethnic subgroup analyses revealed significant increases in cancer risk in the four models among Asians but not among Caucasians. The results became prominent when the six studies that deviated from HWE were excluded (see Supplementary Table 1 and Supplementary Figure 1 in Supplementary Material available online at http://dx.doi.org/10.1155/2014/612972).

3.3. Evaluation of Publication Bias. Publication bias was evaluated by Begg's funnel plot and Egger's test, and the visual asymmetry was determined in the funnel plot analysis (Figure 3). We further evaluated the publication bias in the subgroups. The results of Egger's tests for all genetic models are shown in Supplementary Table 2 (ins allele versus del allele, $P=0.004)$.

\section{Discussion}

NF- $\kappa \mathrm{B}$ serves important functions in pathogenetic regulation and influences cancer development and aggressiveness by enhancing tumour angiogenesis, antiapoptosis, and proliferation and by repressing immune response [7, 33, 34]. Several investigators reported the constitutive activation of $\mathrm{NF}-\kappa \mathrm{B}$ in various malignancies $[35,36]$, including nonsmall cell lung carcinoma and colon, prostate, breast, bone, and brain cancers. p50 overexpression is frequently observed in various tumour tissues; hence, p50 is potentially involved in tumourigenesis. A polymorphism in the promoter region of NFKB1 encoding the p50 subunit of NF- $\kappa \mathrm{B}$ modulates gene activity. This polymorphism has been recently reported to influence cancer risk.

A meta-analysis of all eligible studies in 2010 suggested that the deletion allele serves as a protective or risk allele for cancer susceptibility among Asians or Caucasians, respectively [9]. However, no significant association was detected for the overall population [9]. After the reported study, numerous studies further assessed the relationship between the NFKB1 promoter -94ins/del ATTG polymorphism and cancer among Asians and Caucasians [10, 12, 32]. However, the association remains inconclusive because of the inconsistent results from the published studies. Li et al. [12] found an association between del/del genotype and bladder cancer risk but none between the polymorphism and hepatocellular carcinoma susceptibility [30].

In this study, we analysed 21 eligible case-control studies with 6127 cases and 9239 controls. The results of this metaanalysis revealed a significant association between insertion allele careers and enhanced cancer risk. The probable mechanism behind the observed association may be linked to the enhanced expression and activity of p50 (NF- $\kappa \mathrm{B} 1)$. The insertion allele is reportedly associated with the increased promoter activity and enhanced NFKB1 mRNA expression [8, $12,17]$. This association might influence cancer development.

The major effect of p50 (NF- $\kappa \mathrm{B} 1)$ is mediated by its function as a component of the transcription factor NF$\kappa \mathrm{B}$, which is among the major signalling pathways involved in the cellular response to environmental stress [7]. p50 serves an important function in inhibiting cell apoptosis by modulating the expression levels of several survival genes, such as bcl-2 homologue A1 [37], PAI-2 [38], and IAP gene family [39]. Certain antiapoptosis proteins, such as $\mathrm{Bcl}-\mathrm{xL}$ and Fas-associated death domain-like IL-1-converting enzyme inhibitor protein, are upregulated through the NF$\kappa \mathrm{B}$ signalling pathway [40-42]. In addition, accumulated evidence illustrated that the p50 (NF- $\kappa \mathrm{B} 1)$ signalling pathways participate in cellular proliferation by increasing IL-5 [43], promoting MAPK phosphorylation [7, 44], and modulating cyclin D1 expression [45]. Therefore, the observed association between the-94ins/del ATTG polymorphism and cancer risk can be accounted for by the insertion allele that can inhibit apoptosis and promote cellular proliferation by upregulating the expression of p50 (NFKB1) $[8,12,17]$, which was implicated in the abovementioned mechanism.

In the stratified analyses, the increased cancer risk remained in subgroups of Asians but not in those of Caucasians. The ethnic differences in the allele frequencies may be caused by natural selection or balance to other related genetic variants. Possible differences in genetic backgrounds and gene environment may also interact with the etiology. The increased cancer risk also remained in the subgroups of ovarian, oral, and prostate cancers. This result suggested that the NFKB1 gene might function as a prominent factor in these cancers. Therefore, further investigations are warranted to validate ethnic difference and cancer specificity in the effect of this functional polymorphism on cancer susceptibility.

This study has several limitations. First, significant between-study heterogeneity was detected in some comparisons and may be distorting the meta-analysis. Second, the genotype distribution among controls did not completely agree with HWE. However, the association between the insertion allele and cancer risk in the overall population and in the Asian population became pronounced when the six studies that deviated from HWE were excluded. Third, the studies included in the analysis used different genotyping methods with different quality control issues that may have also influenced the results. Fourth, publication bias was observed 


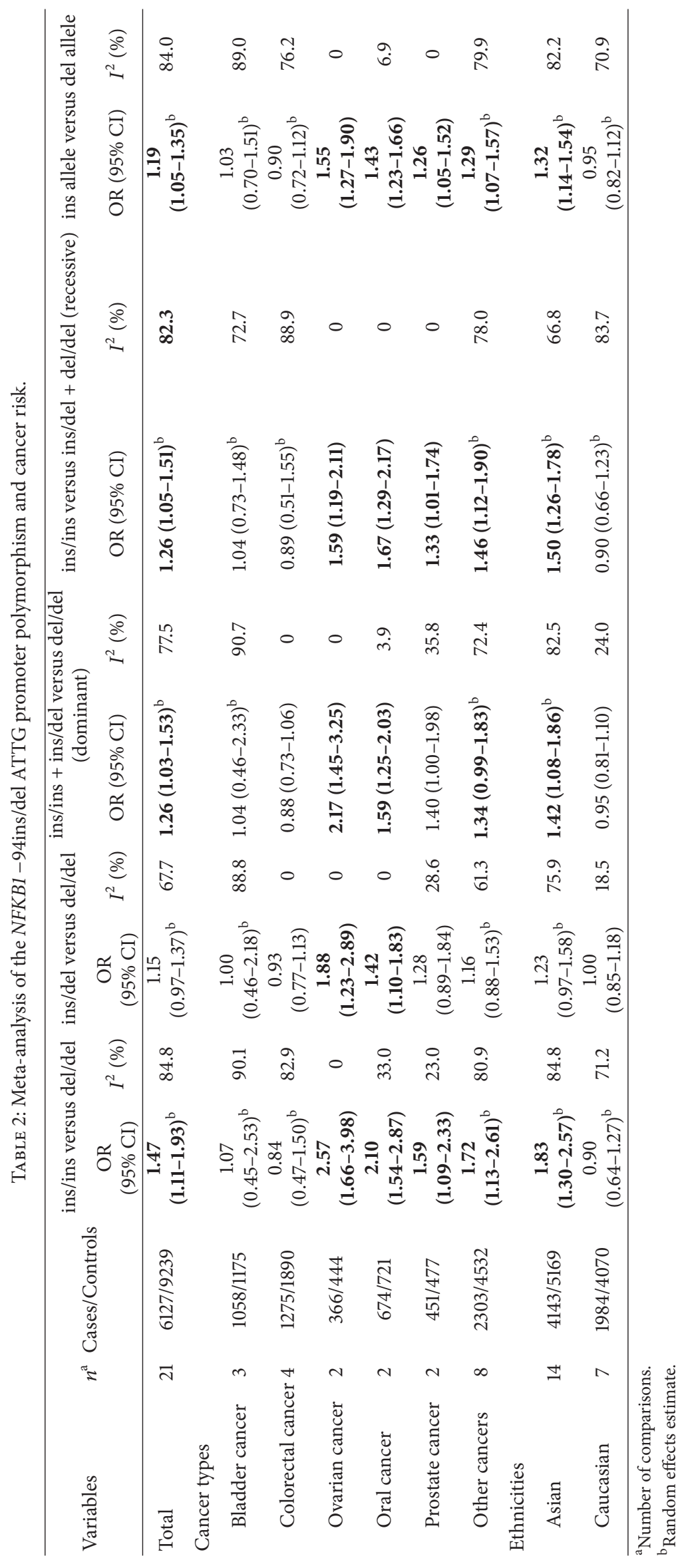




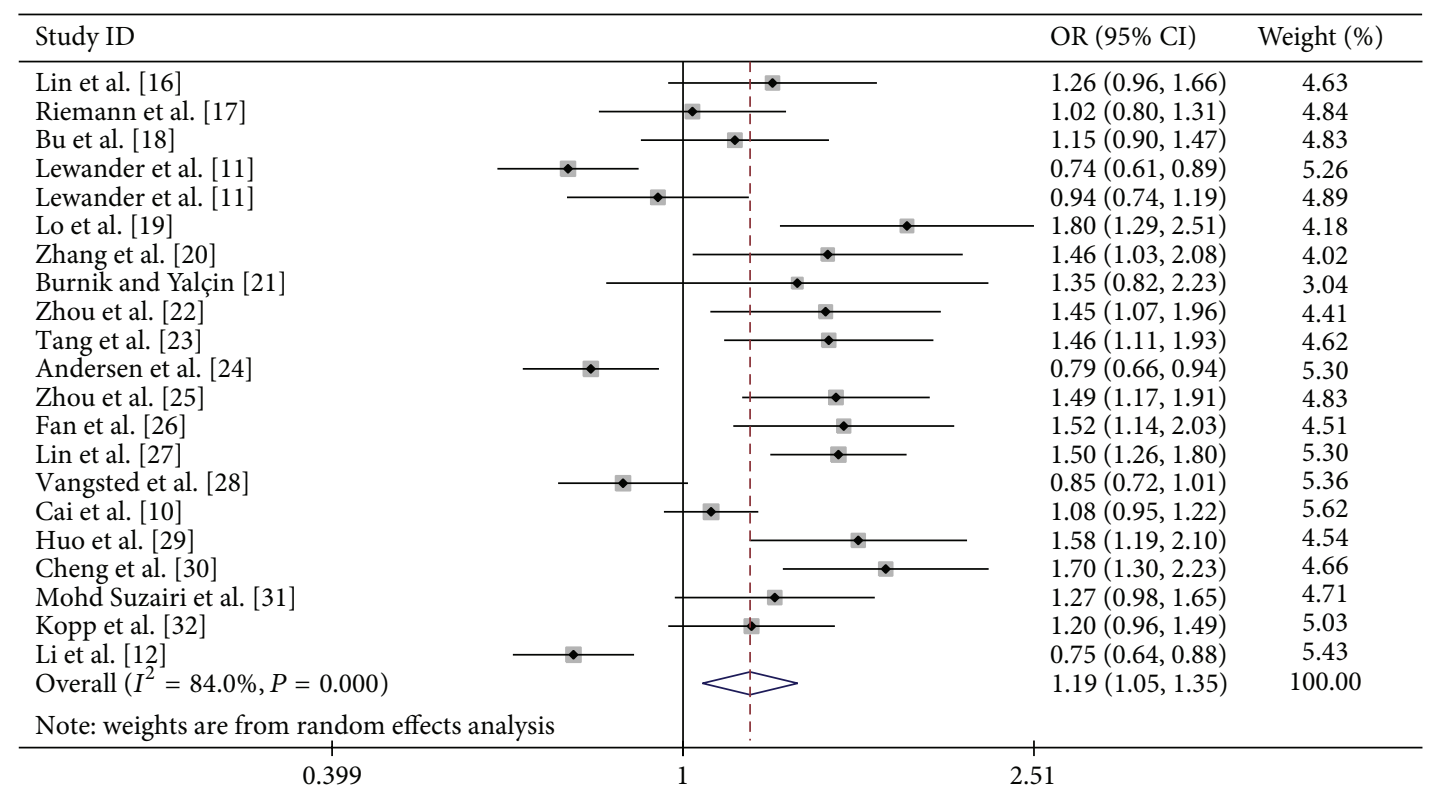

FIGURE 2: Forest plot of cancer risk associated with NFKB1 promoter -94ins/del ATTG polymorphism (for insertion allele versus deletion allele) among all studies.

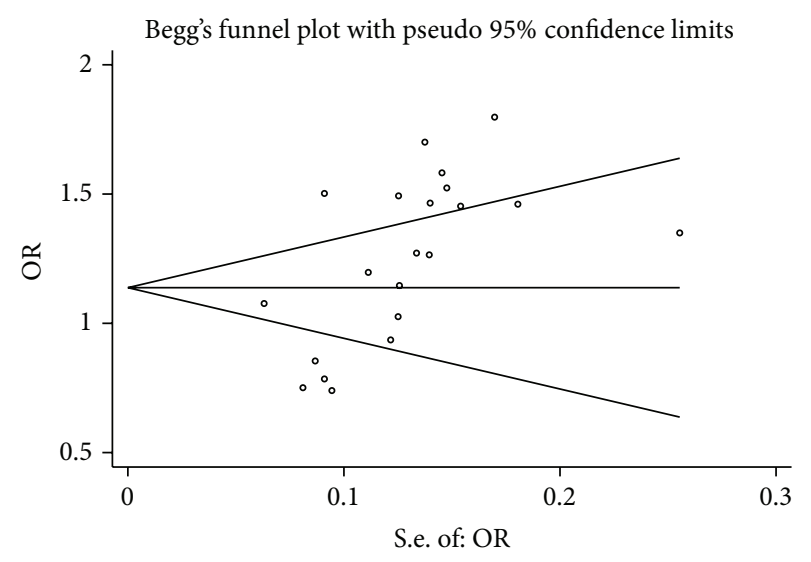

Figure 3: Begg's funnel plot of the association between NFKB1 promoter -94ins/del ATTG polymorphism and cancer risk (ins allele versus del allele).

in our study, which may affect the validity of conclusion. In the stratified analysis, we found that the publication bias was significant among the Asian groups and other cancer groups but not significant among the Caucasian, bladder, and colorectal cancer groups. The sample sizes of the included studies were diverse, and most of them were insufficiently large. These conditions might partly interpret the publication bias. Finally, only three controls were population based; thus, they may not represent the general population. Therefore, the results of this study should be interpreted with caution.

In conclusion, the NFKB1 promoter -94ins/del ATTG polymorphism is associated with cancer risk. Well-designed studies with representative sample sizes are necessary to validate these findings.

\section{Conflict of Interests}

The authors have declared that no conflict of interests exist.

\section{Authors' Contribution}

Xiao Yang, Pengchao Li, and Jun Tao contributed equally to this work.

\section{Acknowledgments}

This work was supported by the Program for Development of Innovative Research Team of the First Affiliated Hospital of Nanjing Medical University, the Provincial Initiative Program for Excellency Disciplines of Jiangsu Province, the National Natural Science Foundation of China (Grant nos. 81272832 and 81201997), the Natural Science Foundation of Jiangsu Province (Grant no. BK2011848), the Six Major Talent Peak Project of Jiangsu Province (Grant no. 2011-WS-121), and the Priority Academic Program Development of Jiangsu Higher Education Institutions (PAPD). The funders had no role in study design, data collection and analysis, decision to publish, or preparation of the paper.

\section{References}

[1] WHO, The GLob L Burden of Disease: 2004 Update, World Health Organization, Geneva, Switzerland, 2008.

[2] W. D. Foulkes, "Inherited susceptibility to common cancers," The New England Journal of Medicine, vol. 359, no. 20, pp. 21432153, 2008.

[3] R. Sen and D. Baltimore, "Inducibility of K immunoglobulin enhancer-binding protein NF-kB by a posttranslational mechanism," Cell, vol. 47, no. 6, pp. 921-928, 1986. 
[4] F. Chen, V. Castranova, X. Shi, and L. M. Demers, "New insights into the role of nuclear factor $-\kappa \mathrm{B}$, a ubiquitous transcription factor in the initiation of diseases," Clinical Chemistry, vol. 45, no. 1, pp. 7-17, 1999.

[5] X. F. Sun and H. Zhang, "NFKB and NFKBI polymorphisms in relation to susceptibility of tumour and other diseases," Histology and histopathology, vol. 22, no. 12, pp. 1387-1398, 2007.

[6] F. Chen, V. Castranova, X. Shi, and L. M. Demers, "New insights into the role of nuclear factor- $\kappa \mathrm{B}$, a ubiquitous transcription factor in the initiation of diseases," Clinical Chemistry, vol. 45, no. 1, pp. 7-17, 1999.

[7] Y. Yu, Y. Wan, and C. Huang, "The biological functions of NF$\kappa \mathrm{B} 1$ (p50) and its potential as an anti-cancer target," Current Cancer Drug Targets, vol. 9, no. 4, pp. 566-571, 2009.

[8] A. S. Karban, T. Okazaki, C. I. M. Panhuysen et al., "Functional annotation of a novel NFKB1 promoter polymorphism that increases risk for ulcerative colitis," Human Molecular Genetics, vol. 13, no. 1, pp. 35-45, 2004.

[9] Y. F. Zou, F. L. Yuan, X. L. Feng et al., "Association between NFKB1 -94ins/delATTG promoter polymorphism and cancer risk: A meta-analysis," Cancer Investigation, vol. 29, no. 1, pp. 78-85, 2011.

[10] H. Cai, L. Sun, L. Cui et al., "Functional insertion/deletion polymorphism (-94 ins/del ATTG) in the promoter region of the NFKB1 gene is related to the risk of renal Cell Carcinoma.," Urologia Internationalis, vol. 91, no. 2, pp. 206-212, 2013.

[11] A. Lewander, A. K. R. Butchi, J. Gao et al., "Polymorphism in the promoter region of the NFKB1 gene increases the risk of sporadic colorectal cancer in Swedish but not in Chinese populations," Scandinavian Journal of Gastroenterology, vol. 42, no. 11, pp. 1332-1338, 2007.

[12] P. Li, J. Gu, X. Yang et al., "Functional promoter -94 ins/del ATTG polymorphism in NFKB1 gene is associated with bladder cancer risk in a chinese population," PLOS ONE, vol. 8, no. 8, Article ID e71604, 2013.

[13] W. G. Cochran, "The comparison of percentages in matched samples," Biometrika, vol. 37, no. 3-4, pp. 256-266, 1950.

[14] M. Egger, G. D. Smith, M. Schneider, and C. Minder, "Bias in meta-analysis detected by a simple, graphical test," British Medical Journal, vol. 315, no. 7109, pp. 629-634, 1997.

[15] A. E. Stuck, L. Z. Rubenstein, and D. Wieland, "Bias in meta-analysis detected by a simple, graphical test. Asymmetry detected in funnel plot was probably due to true heterogeneity," British Medical Journal, vol. 316, no. 7129, pp. 469-471, 1998.

[16] S. C. Lin, C. J. Liu, W. I. Yeh, M. T. Lui, K. W. Chang, and C. S. Chang, "Functional polymorphism in NFKB1 promoter is related to the risks of oral squamous cell carcinoma occurring on older male areca (betel) chewers," Cancer Letters, vol. 243, no. 1, pp. 47-54, 2006.

[17] K. Riemann, L. Becker, H. Struwe, H. Rübben, A. Eisenhardt, and W. Siffert, "Insertion/deletion polymorphism in the promoter of NFKB1 as a potential molecular marker for the risk of recurrence in superficial bladder cancer," International Journal of Clinical Pharmacology and Therapeutics, vol. 45, no. 8, pp. 423-430, 2007.

[18] H. Bu, I. Rosdahl, X. F. Sun, and H. Zhang, "Importance of polymorphisms in NF-kappaB1 and NF-kappaBIalpha genes for melanoma risk, clinicopathological features and tumor progression in Swedish melanoma patients., Journal of Cancer Research and Clinical Oncology, vol. 133, no. 11, pp. 859-866, 2007.
[19] S. S. Lo, J. H. Chen, C. W. Wu, and W. Y. Lui, "Functional polymorphism of NFKB1 promoter may correlate to the susceptibility of gastric cancer in aged patients," Surgery, vol. 145, no. 3, pp. 280-285, 2009.

[20] P. Zhang, Q. Wei, X. Li et al., "A functional insertion/deletion polymorphism in the promoter region of the NFKB1 gene increases susceptibility for prostate cancer," Cancer Genetics and Cytogenetics, vol. 191, no. 2, pp. 73-77, 2009.

[21] F. S. Burnik and S. Yalçin, "NFKB1 -94 insertion/deletion ATTG polymorphism in gastroenteropancreatic neuroendocrine tumors," Chemotherapy, vol. 55, no. 5, pp. 381-385, 2009.

[22] B. Zhou, L. Rao, Y. Li et al., "A functional insertion/deletion polymorphism in the promoter region of NFKB1 gene increases susceptibility for nasopharyngeal carcinoma," Cancer Letters, vol. 275, no. 1, pp. 72-76, 2009.

[23] T. Tang, S. Cui, X. Deng et al., "Insertion/deletion polymorphism in the promoter region of NFKB1 gene increases susceptibility for superficial bladder cancer in Chinese," DNA and Cell Biology, vol. 29, no. 1, pp. 9-12, 2010.

[24] V. Andersen, J. Christensen, K. Overvad, A. Tjønneland, and U. Vogel, "Polymorphisms in NFkB, PXR, LXR and risk of colorectal cancer in a prospective study of Danes," BMC Cancer, vol. 10, article 484, 2010.

[25] B. Zhou, M. Qie, Y. Wang et al., "Relationship between NFKB1 -94 insertion/deletion ATTG polymorphism and susceptibility of cervical squamous cell carcinoma risk," Annals of Oncology, vol. 21, no. 3, Article ID mdp507, pp. 506-511, 2009.

[26] Y. Fan, W. Yu, P. Ye et al., "NFKB1 insertion/deletion promoter polymorphism increases the risk of advanced ovarian cancer in a Chinese population," DNA and Cell Biology, vol. 30, no. 4, pp. 241-245, 2011.

[27] C. W. Lin, Y. S. Hsieh, C. H. Hsin et al., "Effects of NFKB1 and NFKBIA gene polymorphisms on susceptibility to environmental factors and the clinicopathologic development of oral cancer," PLoS ONE, vol. 7, no. 4, Article ID e35078, 2012.

[28] A. J. Vangsted, K. R. Nielsen, T. W. Klausen, E. Haukaas, A. Tjønneland, and U. Vogel, "A functional polymorphism in the promoter region of the IL1B gene is associated with risk of multiple myeloma," British Journal of Haematology, vol. 158, no. 4, pp. 515-518, 2012.

[29] Z. H. Huo, H. J. Zhong, Y. S. Zhu, B. Xing, and H. Tang, "Roles of functional NFKB1 and $\beta$-TrCP insertion/deletion polymorphisms in mRNA expression and epithelial ovarian cancer susceptibility," Genetics and Molecular Research, vol. 12, no. 3, pp. 3435-3443, 2013.

[30] C. W. Cheng, J. L. Su, C. W. Lin et al., "Effects of NFKB1 and NFKBIA gene polymorphisms on hepatocellular carcinoma susceptibility and clinicopathological features," PLOS ONE, vol. 8, no. 2, Article ID e56130, 2013.

[31] M. S. Mohd Suzairi, S. C. Tan, A. A. Ahmad Aizat et al., “The functional -94 insertion/deletion ATTG polymorphism in the promoter region of NFKB1 gene increases the risk of sporadic colorectal cancer," Cancer Epidemiology, vol. 37, no. 5, pp. 634638, 2013.

[32] T. I. Kopp, S. Friis, J. Christensen, A. Tjønneland, and U. Vogel, "Polymorphisms in genes related to inflammation, NSAID use, and the risk of prostate cancer among Danish men," Cancer Genetics, vol. 206, no. 7-8, pp. 266-78, 2013.

[33] M. Karin, "Nuclear factor- $\kappa \mathrm{B}$ in cancer development and progression," Nature, vol. 441, no. 7092, pp. 431-436, 2006. 
[34] Q. Li and I. M. Verma, "NF-kappaB regulation in the immune system," Nature Reviews Immunology, vol. 2, no. 10, pp. 725-734, 2002.

[35] T. Mukhopadhyay, J. A. Roth, and S. A. Maxwell, "Altered expression of the p50 subunit of the NF- $\kappa \mathrm{B}$ transcription factor complex in non-small cell lung carcinoma," Oncogene, vol. 11, no. 5, pp. 999-1003, 1995.

[36] V. Bours, E. Dejardin, F. Goujon-Letawe, M. P. Merville, and V. Castronovo, "The NF- $\kappa \mathrm{B}$ transcription factor and cancer: high expression of NF- $\kappa \mathrm{B}$ - and I $\kappa \mathrm{B}$-related proteins in tumor cell lines," Biochemical Pharmacology, vol. 47, no. 1, pp. 145-149, 1994.

[37] A. Karsan, E. Yee, K. Kaushansky, and J. M. Harlan, “Cloning of a human Bcl-2 homologue: inflammatory cytokines induce human A1 in cultured endothelial cells," Blood, vol. 87, no. 8, pp. 3089-3096, 1996.

[38] S. Kumar and C. Baglioni, "Protection from tumor necrosis factor-mediated cytolysis by overexpression of plasminogen activator inhibitor Type-2," Journal of Biological Chemistry, vol. 266, no. 31, pp. 20960-20964, 1991.

[39] E. C. LaCasse, S. Baird, R. G. Korneluk, and A. E. MacKenzie, "The inhibitors of apoptosis (IAPs) and their emerging role in cancer," Oncogene, vol. 17, no. 25, pp. 3247-3259, 1998.

[40] H. P. Glauert, J. C. Tharappel, S. Banerjee et al., "Inhibition of the promotion of hepatocarcinogenesis by $2,2^{\prime}, 4,4^{\prime}, 5,5^{\prime}$ hexachlorobiphenyl (PCB-153) by the deletion of the p50 subunit of NF- $\kappa \mathrm{B}$ in mice," Toxicology and Applied Pharmacology, vol. 232, no. 2, pp. 302-308, 2008.

[41] E. D. Cahir-McFarland, D. M. Davidson, S. L. Schauer, J. Duong, and E. Kieff, "NF- $\kappa$ B inhibition causes spontaneous apoptosis in Epstein-Barr virus-transformed lymphoblastoid cells," Proceedings of the National Academy of Sciences of the United States of America, vol. 97, no. 11, pp. 6055-6060, 2000.

[42] L. Bernal-Mizrachi, C. M. Lovly, and L. Ratner, "The role of NF- $\kappa$ B-1 and NF- $\kappa$ B-2-mediated resistance to apoptosis in lymphomas," Proceedings of the National Academy of Sciences of the United States of America, vol. 103, no. 24, pp. 9220-9225, 2006.

[43] L. Yang, L. Cohn, D. H. Zhang, R. Homer, A. Ray, and P. Ray, "Essential role of nuclear factor $\kappa \mathrm{B}$ in the induction of eosinophilia in allergic airway inflammation," Journal of Experimental Medicine, vol. 188, no. 9, pp. 1739-1750, 1998.

[44] D. Artis, C. M. Kane, J. Fiore et al., "Dendritic cell-intrinsic expression of NF- $\kappa \mathrm{B} 1$ is required to promote optimal Th2 cell differentiation," Journal of Immunology, vol. 174, no. 11, pp. 71547159, 2005.

[45] S. Shukla, G. T. MacLennan, S. R. Marengo, M. I. Resnick, and S. Gupta, "Constitutive activation of PI3K-Akt and NF- $\kappa$ B during prostate cancer progression in autochthonous transgenic mouse model," Prostate, vol. 64, no. 3, pp. 224-239, 2005. 

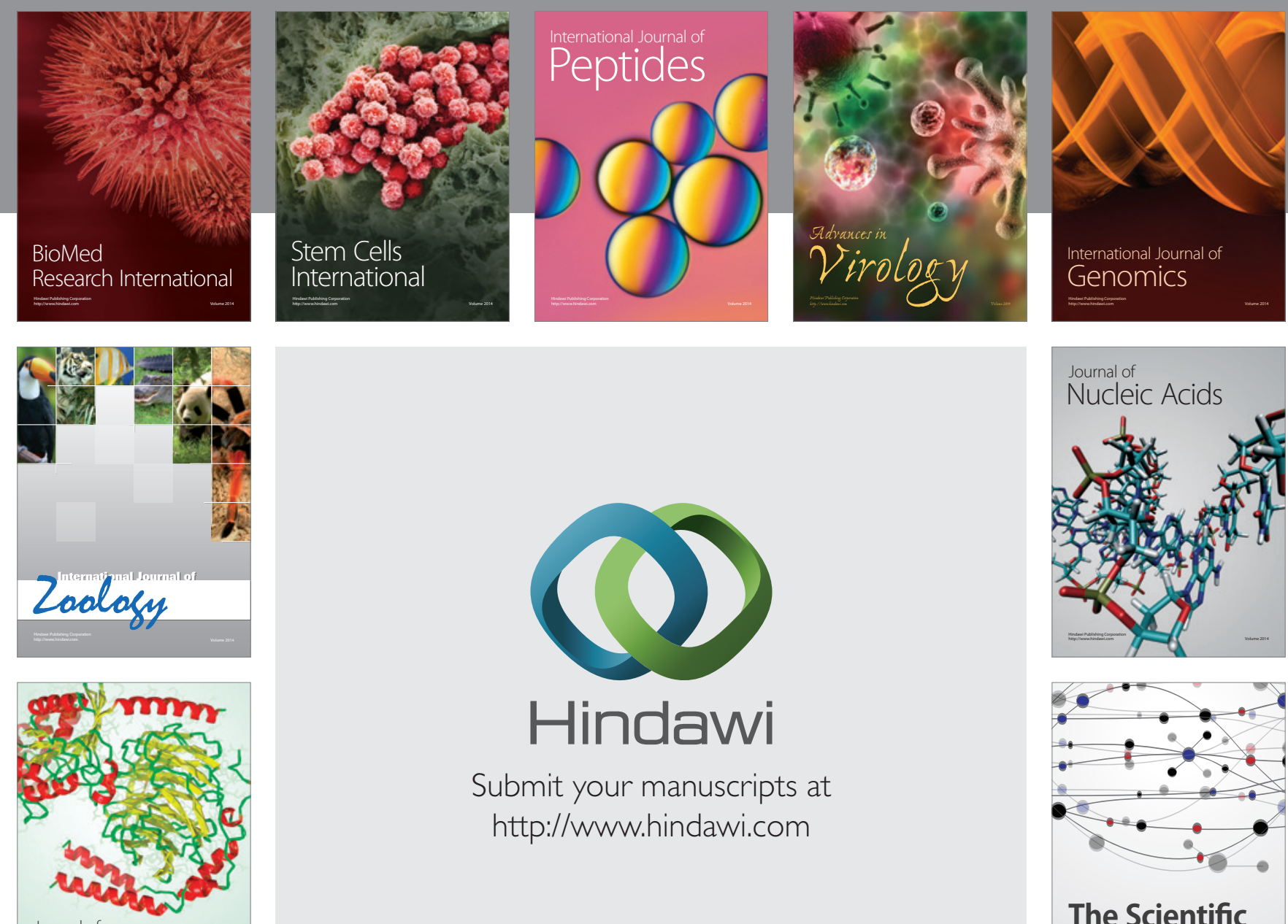

Submit your manuscripts at

http://www.hindawi.com

Journal of
Signal Transduction
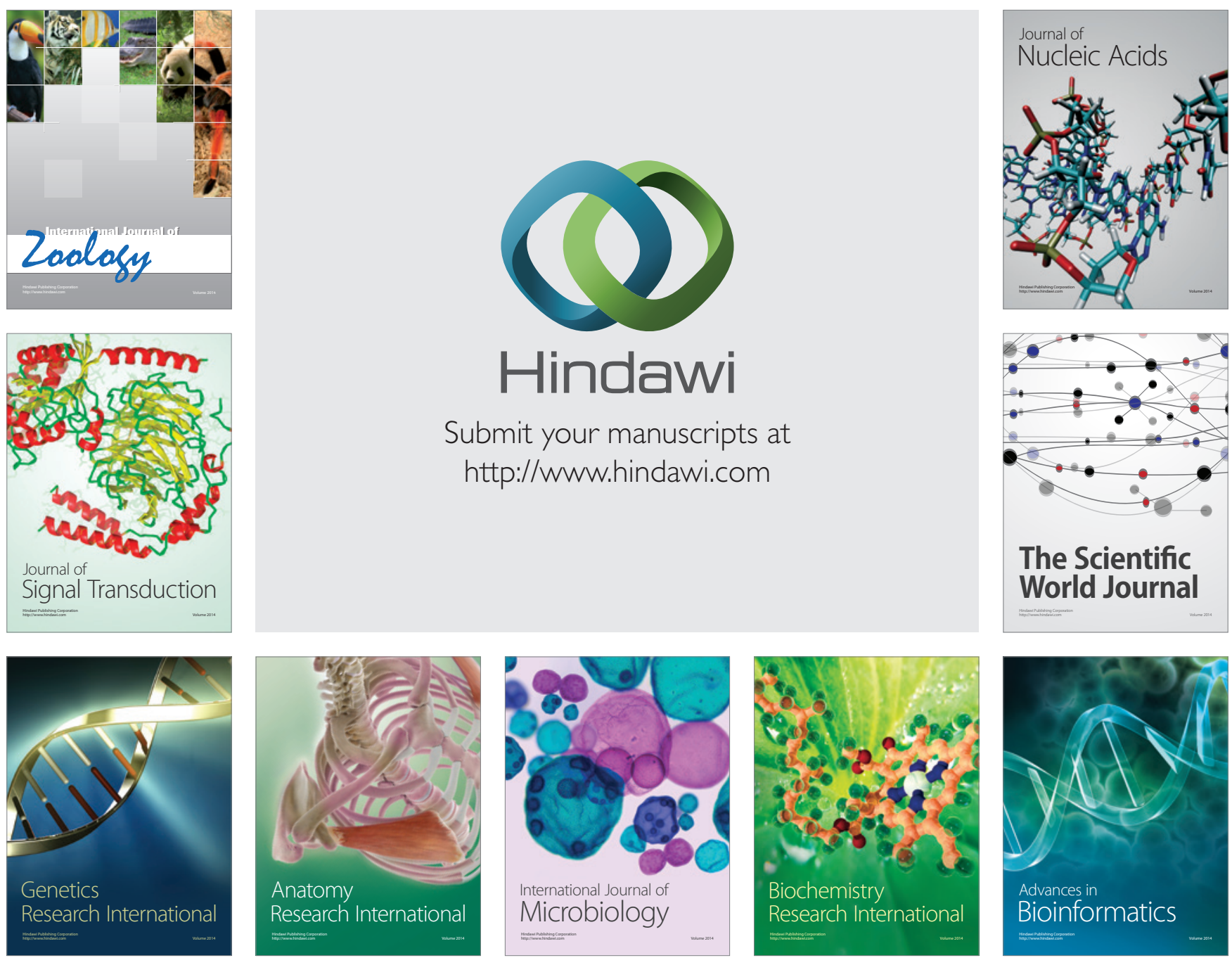

The Scientific World Journal
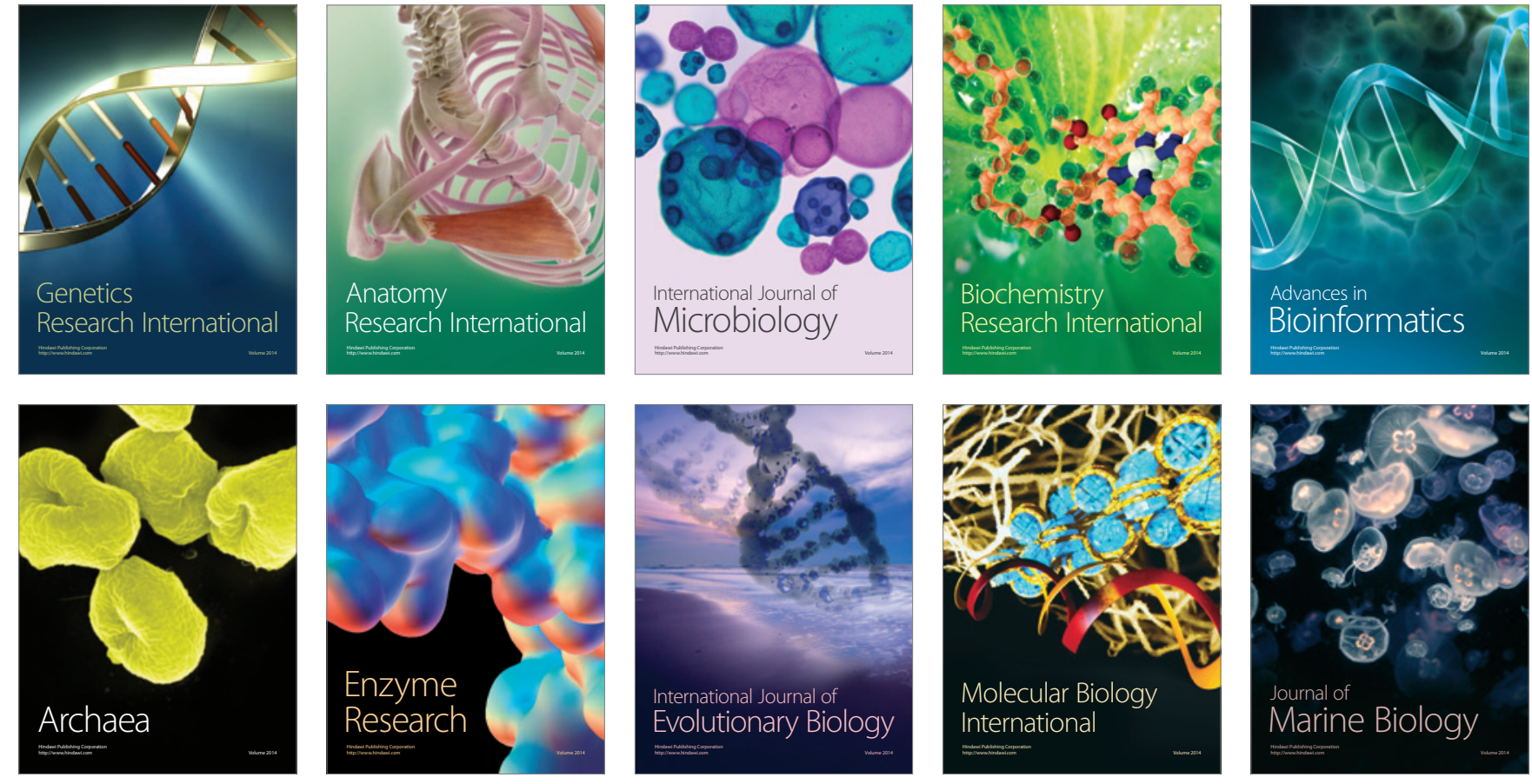